\title{
Teatro do oprimido e o desenvolvimento saudável da sexualidade de jovens na escola
}

\section{Theater of the oppressed and the healthy development of sexuality of young people in school}

\author{
Diego Saimon de Souza Abrantes 1, Jéssica dos Santos Ramos 2, Yasmin Danielle \\ Marques Xavier 3
}

${ }_{1}^{1}$ sicólogo, Coach e Docente na Universidade Estadual do Amapá e Instituto Macapaense do Melhor Ensino Superior. Macapá-AP Brasil. Email: diego_saimon@hotmail.com *Autor para correspondência.

${ }^{2}$ Acadêmica de Psicologia, Instituto Macapaense do Melhor Ensino Superior. Macapá-AP Brasil. E-mail: jessicaramos066@gmail.com

${ }^{3}$ Acadêmica de Psicologia, Instituto Macapaense do Melhor Ensino Superior. Macapá-AP Brasil. E-mail: seusegundosol@gmail.com

\section{Palavras-chave \\ Teatro do oprimido \\ Sexualidade \\ Escola}

O estudo aborda a análise do Teatro do Oprimido (TO) e sua contribuição na compreensão saudável do desenvolvimento da sexualidade de jovens na escola. Teve como objetivos discutir o uso do TO no ambiente escolar, analisar o desenvolvimento da sexualidade dos adolescentes e correlacionar ambos os temas. A pesquisa qualitativa, utilizou-se de método bibliográfico, tendo cunho descritivo e centrou-se na sexualidade de jovens dos 15 aos 17 anos. Realizou-se análise correlacional de 76 obras, entre artigos científicos, livros, dissertações e teses, com informações coletadas organizadas em fichas. Os artigos foram encontrados nos indexadores Portal Scielo e CAPES. Foram usadas palavras-chaves como filtros: Teatro do oprimido; desenvolvimento da sexualidade; adolescentes e escola. Para análise, separaram-se as obras em um trio de temas: TO; desenvolvimento da sexualidade de jovens na escola; e a correlação entre TO e Desenvolvimento da Sexualidade na escola. A interpretação dos dados feitas pelos pesquisadores ocorreu através do método analítico. Os resultados demonstram que o TO é uma metodologia capaz de transformar concepções que causam sofrimento psíquico ao adolescente na escola, levando-o a comportamentos de risco. Através do mecanismo de troca de papeis entre as figuras opressoras e oprimidas em cena, o TO permite ao jovem a abstração das ansiedades e angústias próprias do período e consequente condições mentais para acepção de posturas mais saudáveis perante os desafios sociais da adolescência. Percebeu-se, inclusive, que além do trabalho remediador, o TO tem influente papel de prevenção de comportamentos nocivos à saúde dos jovens de 15 aos 17 anos.

\section{Keywords \\ Theater of the oppressed Sexuality \\ School}

\begin{abstract}
The present study deals with the analysis of the Theater of the Oppressed (TO) and its contribution to a healthy understanding of the development of sexuality among 15 to 17 year olds within the school. It aimed to discuss the use of TO in the school environment, to analyze the development of adolescents' sexuality, and to correlate, analytically, both themes. The bibliographic method was used, and the research was descriptive, qualitative and of an applied nature. Correlational analysis was performed through 76 pieces of paper collected. The results demonstrate that TO is a methodology of great importance to demystify concepts, to understand aspects and to propose interventions of how the sexual education can be worked in the school before an integral vision of the subject. By proposing that young people bring to reality issues related to the development of their sexuality, actors and spectators, oppressors and oppressors, begin to visualize how their behaviors and conceptions influence one another's life, allowing a role change and the discussion of behaviors and healthier postures, as well as the exchange of information about questions and doubts about their own development. Through the analyzes carried out, it was concluded that since school is one of the main institutions that will prepare young people for life in society, it is here the first interventions in the development of the learning of actions aimed at the promotion of a healthy sexuality and the prevention of behaviors by performing TO.
\end{abstract}


Quando se relaciona esse ambiente ao período da adolescência, que é composto por mudanças e transformações biopsicossociais, como na sexualidade, as relações que são estabelecidas durante essa fase se não forem bem elaboradas, podem trazer consequências negativas ao seu desenvolvimento (BRILHANTE; CATRIB, 2011; ALENCAR; FRANCISCHINI, 2016).

Estabeleceu-se como questão norteadora a problemática que buscou delimitar como o Teatro do Oprimido (TO) poderia auxiliar os adolescentes durante o desenvolvimento da sua sexualidade dentro do ambiente escolar. Assim, definiu-se como objetivo analisar qual a sua contribuição para a compreensão e promoção saudável do desenvolvimento da sexualidade de jovens de 15 a 17 anos na escola. O presente artigo é resultado de um ano de pesquisa.

Através de análise correlacional dos temas, demonstrouse que a hipótese de que o TO pode e colabora no processo de aprendizado, reflexão e amadurecimento do adolescente diante de sua própria sexualidade é verdadeira. Soma-se ainda o fato de que desse modo, com esse método, o educando tem mais conhecimento e suporte emocional para desenvolver-se sexualmente sem colocar em risco à própria vida e a de outras pessoas.

\section{Teatro do oprimido}

O TO nasceu em 1960 durante o auge da ditadura militar, com o objetivo inicial de representar os temas políticos mais urgentes tendo como precursor o teatrólogo Augusto Boal. O método desconstrói obstáculos padronizados, sendo inspiração na busca de possibilidades eficazes para aumentar a participação da comunidade e fazer com que ela se envolva durante o espetáculo, a fim de compreender quais os efeitos deste elemento e sentir os resultados práticos. De acordo com a Associação Internacional do Teatro do Oprimido (AITO, 2012), um dos mais importantes objetivos, dentre todos os identificados, é restabelecer o diálogo entre as pessoas promovendo um contato mais humano que evite a construção e/ou manutenção de relações opressoras e oprimidas (OLIVEIRA; ARAúJO, 2012).

A promoção de relações livres e igualitárias, seja individual ou coletiva, assemelha-se à ideologia democrática participativa que, muitas vezes, torna-se utópica, uma vez que as relações de poder encontradas na estruturação da sociedade podem ser repensadas e redefinidas (CAMPOS; PINTO; SAEKI, 2014). Assim sendo, essas participações podem ser entendidas como um mecanismo de enfrentamento a essas dominações de poder, que reafirma os direitos conquistados ao longo do tempo com a luta histórica das classes trabalhadoras, dos povos segregados e da minoria excluída socialmente.

Analisa-se que a junção dos objetivos em busca de expandir os diversos contextos de atuação do TO pode aliviar as opressões vivenciadas pelos indivíduos facilitando a compreensão e a transformação dos papéis durante a encenação. Há inversão de papéis, pois o opressor passa para o lugar do oprimido, e este para o lugar do opressor, possibilitando uma troca de sentimentos. A partir dessa percepção, tanto um quanto o outro visualizam seus posicionamentos passam a compreender quais parâmetros estão por traz de seus comportamentos. Diante desse contexto, considera-se o diálogo um dos maiores benefícios trazidos aos sujeitos diante das várias maneiras de atuação e dos diversos temas possíveis que podem ser abordados pelo TO, como o aqui delimitado, desenvolvimento saudável da sexualidade.

\section{Desenvolvimento saudável da sexualidade}

O período entre os 15 e 17 anos apresenta-se como um momento de ocorrência de inúmeras mudanças em diversos contextos da vida do jovem, como o processo de estabelecimento da identidade, a puberdade e seu pico biológico, as crises e conflitos do sujeito consigo e com o meio social, as responsabilidades por estar chegando à maioridade, dentre outros. Diante disso, é necessário que o adolescente tenha acesso às informações sobre anatomia, fisiologia, contracepção e prevenção de doenças (BRILHANTE; CATRIB, 2011).

Segundo Caldeira (2015), no período identificado como adolescência intermédia (15 a 17 anos), observa-se um comportamento menos autocêntrico do jovem. Ele desenvolve uma maior capacidade de ceder às questões que considera importante. Começa a realizar experiências constantemente na busca de uma autoimagem que the satisfaça. Aprende a pensar por si e tomar suas próprias decisões, permitindo novas experiências, testando seus limites e, assim, podendo conhecer os riscos e consequências que suas atitudes podem gerar. As amizades são mais duradouras e íntimas, passa a observar a própria sexualidade com maior ênfase e constituir relacionamentos sexuais envolvendo novos sentimentos, individualizar-se em relação à família e a manifestar comportamentos com o objetivo de analisar a reação dos pais.

Passando de uma visão orgânica e reprodutora para um delineamento conceitual que valoriza além dos aspectos biológicos, sociais, psicológicos, culturais e ambientais, discorrer sobre o que as ciências entendem como desenvolvimento sexual saudável é salutar.

O conceito utilizado, neste estudo, como base para o desenvolvimento saudável da sexualidade refere-se ao que 
Santos (2011) afirma sobre a importância do conhecimento preciso, consciência pessoal e autoaceitação, em que os comportamentos, valores e emoções são congruentes e se relacionam através da personalidade e autodefinição do indivíduo. Sejam por características interpessoais (capacidade de ter intimidade com o parceiro, ter desejos sexuais, de atuar de maneira deliberada e responsável, assim como, estipular limites) como por aspectos comunitários (respeito e valorização pelas diferenças e diversidades, sentimento de pertencimento e participação de uma determinada cultura sexual), o "saudável" vai muito além da inexistência de patologia.

Yano e Ribeiro (2011) dizem que esse desenvolvimento saudável estaria relacionado ao direito dos indivíduos de ter acesso às informações e ao exercício pleno de sua sexualidade, diante de um contexto biológico, social e psicológico favoráveis a esse desenvolvimento.

Edwards e Coleman (2004 apud PONTES, 2011) compreendem a saúde sexual como a capacidade de experimentar a sexualidade livremente, sem riscos de DST, gravidez indesejada, violência, discriminação e coerção. Portanto, para ser saudável sexualmente o indivíduo deveria ter relações sexuais seguras, agradáveis e bem informadas, primando por uma autoestima positiva e respeito mútuo.

Sendo assim, o conceito de desenvolvimento saudável da sexualidade está atrelado à concepção de que o indivíduo tenha direito ao acesso de informações, podendo assim, manifestar sua sexualidade livremente, sem discriminações, valorizando as diferenças, compreendendo as responsabilidades e os riscos de seus comportamentos, através da promoção de uma visão integral do sujeito e que abarque todos os contextos em que está inserido, bem como a possibilidade de se proporcionar um ambiente facilitador.

\section{MÉTODOS}

\section{Caracterização do estudo}

Foi utilizado o método bibliográfico e documental, pois este consiste em realizar pesquisas desenvolvidas através de materiais já elaborados, como livros e artigos científicos, além de documentos que ainda não passaram por uma análise, ou que ainda podem ser reelaborados de acordo com os objetivos da pesquisa. Também teve cunho descritivo, por descrever características de uma determinada população ou fenômeno assim como estabelecer uma relação entre as variáveis (GIL, 2008).

O estudo foi qualitativo, já que não se preocupou com uma representatividade numérica e sim com uma maior compreensão de um determinado grupo social ou de uma organização. De natureza aplicada, proporcionou-se a construção de conhecimentos que podem ser utilizados para aplicação prática, dirigindo-se à solução de problemas específicos (GERHARDT; SILVEIRA, 2009). Atingiu-se a marca amostral de 76 obras analisadas durante a pesquisa ao longo do ano.

A faixa etária definida para se pensar na sexualidade eram de pessoas entre 15 a 17 anos, que se justifica devido ser um intervalo pertencente à adolescência, que de acordo com Bock, Furtado e Teixeira (2001), é um período de transição para a vida adulta, com características sociais e implicações na personalidade e identidade dos jovens, bem como suas identificações, conflitos e crises com o meio social em que está inserido. Tratando-se de uma pesquisa que envolveu a escola, é pertinente dizer que tais idades correspondem ao período em que os jovens estão ingressando e saindo do período escolar do ensino médio, de acordo com a lei no 9.394 de 20 de dezembro de 1996, da Lei de Diretrizes e Bases (LDB) (BRASIL, 1996).

\section{Critérios de inclusão e exclusão}

- Foram utilizadas como fontes de pesquisa: artigos científicos, livros e publicações em universidades.

- As publicações em universidades dividiram-se em dissertações de mestrado e teses de doutorado e pós-doutorado.

- Os artigos foram encontrados nas redes: Portal Scielo e CAPES.

- Os artigos apresentaram como palavras-chaves: Teatro do oprimido; desenvolvimento da sexualidade; adolescentes e escola.

- Os livros estavam de acordo com a temática proposta e as pesquisadoras realizaram uma avaliação para a escolha de cada um.

- Foram excluídas todas as fontes bibliográficas que se diferem ao supracitado.

\section{Coleta, análise e interpretação dos dados}

As informações foram coletadas através de fichas de documentação, que segundo Gil (2008), são fichas para anotações dos elementos mais importantes obtidos com a análise do material pesquisado e que constituem a matériaprima do trabalho. Após a coleta, os dados foram minunciosamente estudados para o entendimento e a seleção dos aspectos mais importantes para a pesquisa. Delimitou-se três grupos de análises das obras: Teatro do Oprimido; desenvolvimento da sexualidade de jovens na escola; e a correlação entre Teatro do Oprimido e 
Desenvolvimento da Sexualidade na escola. Salienta-se que a interpretação de tais dados foi de total responsabilidade das pesquisadoras, que utilizaram o método analítico, que se entende como àquele em que se faz detalhada análise dos aspectos encontrados no processo do estudo (GIL, 2008).

\section{RESULTADOS E DISCUSSÃO}

Para Silveira (2009), o TO pode ser integrado por diversos elementos teatrais, com características únicas, e ser utilizado em várias circunstâncias. A partir disso, ao ser trabalhada a educação sexual nas escolas, através dele, realiza-se atividades voltadas a questões subjetivas, vivências, afetos, influências psicológicas, sociais, dentre outros, que envolvem todos os contextos no qual a sexualidade está inserida, levando assim a um desenvolvimento saudável da sexualidade.

\section{Desenvolvimento saudável da sexualidade na escola}

O TO é um importante instrumento na educação dos jovens, principalmente ao propor o desenvolvimento de uma sexualidade saudável, uma vez que valoriza as experiências dos adolescentes na realidade escolar, proporcionando a eles um fazer artístico que permite o contato com questões vivenciadas diariamente na escola, na tentativa de expressar os seus sentimentos oprimidos, sem a perda das características artísticas, auxiliando na reflexão dos assuntos referentes à temática.

O conceito de desenvolvimento saudável da sexualidade está relacionado ao direito de acesso às informações, exercício pleno da sexualidade em níveis biológicos, sociais e psicológicos favoráveis, assim como conhecimento preciso, consciência pessoal e autoaceitação (SANTOS, 2011; YANO; RIBEIRO, 2011; PONTES, 2011).

Para se ter uma sexualidade saudável, é necessário que o indivíduo e as instituições no qual ele está inserido promovam o diálogo, discussões e até mesmo representações de temas mesmo que considerados polêmicos, auxiliando, dessa forma, o desenvolvimento mental dos jovens diante de uma compreensão mais ampla e positiva da sexualidade. Logo, é necessário que eles estejam acessíveis a expressar seus anseios e dúvidas.

É durante o período de vida dos 15 aos 17 anos que os jovens desenvolvem uma maior capacidade de ceder aos temas considerados importantes, que aprendem a pensar por si, tomar suas próprias decisões passando a conhecer os riscos e consequências de suas atitudes (CALDEIRA, 2015). Portanto, diante desse contexto, ganha importância a realização de intervenções que promovam o desenvolvimento saudável da sexualidade dentro da escola.

Ao articular essas informações com as observadas na estrutura do TO, em que um dos seus objetivos principais é o de reestabelecer o diálogo entre as pessoas para assim promover um contato que possibilite a construção e/ou manutenção de relações não opressoras e/ou oprimidas (CAMPOS; PINTO; SAEKI, 2014), pode-se passar a utilizá-lo como uma metodologia de socialização na escola, de inclusão dos adolescentes no meio social e na luta contra as opressões vivenciadas dentro e fora daquele ambiente.

Diante disso, as contribuições recorrentes do TO, são bastantes evidentes devido ao teatro ter uma linguagem universal, que pode ser compreendida por todos e as pessoas serem naturalmente teatrais. Em vista disso, ele pode ser utilizado em diversas circunstâncias, incluindo a exploração de temas da sexualidade, possibilitando aos espectadores uma participação ativa nas encenações (OLIVEIRA; ARAÚJO, 2012; SILVEIRA, 2009; BORGES; JUNIOR, 2013).

Ele também proporciona aos alunos uma reflexão sobre temas voltados a sexualidade que muitas vezes são tratados como tabus no meio social, como:

- O funcionamento dos métodos contraceptivos e de proteção às Doenças Sexualmente Transmissíveis (DST), fato que pode gerar uma redução no índice de gravidez na adolescência e na proliferação das DST;

- A maneira de se comportar diante do preconceito e da discriminação contra indivíduos com a orientação sexual diferente da heterossexual, como as Lésbicas, Gays, Bissexuais, Travestis, Transexuais ou Transgêneros (LGBTs);

- A violência e o assédio sexual cometido contra homens e mulheres;

- O consumo de bebidas alcoólicas e outras drogas em decorrência de conflitos da sexualidade como meio de fuga da realidade;

- A prostituição como comércio do corpo, na busca da aquisição de recursos financeiros, que os coloca em situação de risco.

Consequentemente, ao se relacionar a educação com a arte, o processo de aprendizagem torna-se mais libertador e transformador, visto que ao representar situações vivenciadas no ambiente escolar, professores e alunos assumem a postura de atores e espectadores em pequenos espetáculos e podem transformar a realidade em que estão inseridos em um ambiente facilitador para lidar com os mais variados obstáculos que venham a surgir. É dessa maneira que o TO possibilita a identificação de práticas opressoras e 
aponta caminhos com mais diálogo que podem ser utilizados na construção do conhecimento e no desenvolvimento da aprendizagem (SILVA, 2010; FILHO; MARQUES, 2012).

Destarte, através do TO, as informações sobre a sexualidade são repassadas e desenvolvidas de maneira clara e objetiva, visto que esta metodologia proporciona a todos os envolvidos um contato direto com suas dúvidas, conceitos, pré-conceitos e experiências, o que facilita um desenvolvimento saudável da sexualidade, porquanto, ao compreender os comportamentos nocivos, estes podem ser modificados e aqueles que são oprimidos podem ser ressignificados.

\section{Promoção, prevenção e a sexualidade na escola}

Após a identificação de como o TO auxilia na compreensão de um desenvolvimento saudável da sexualidade, é importante ressaltar como ele pode contribuir na promoção do mesmo, visto que se entende a sexualidade como um conceito amplo que envolve diversos temas.

Diante dos resultados, comprovou-se que sua utilização diante de temas como gravidez na adolescência, aborto, DST, autoaceitação, suicídio e tantos outros, quando trabalhados dentro do contexto escolar, promove um desenvolvimento mais positivo e enriquecedor no que se relaciona à aprendizagem e a aquisição de conhecimentos, bem como a prevenção de comportamentos considerados nocivos à saúde dos jovens.

Esta comprovação é observada através da necessidade e da importância de se debater e discutir com os jovens, as questões voltadas a sua sexualidade, principalmente aquelas referentes à anatomia, fisiologia, contracepção, prevenção de doenças, reprodução de condutas violentas e estigmas sociais. Busca-se a efetivação de um desenvolvimento sexual saudável, que valorize o bem estar, pois as mudanças e transformações que cada um vivencia durante esse período podem ser influenciadas de maneira positiva ou negativa (BRILHANTE; CATRIB, 2011; ALENCAR; FRANCISCHINI, 2016).

Para a promoção de uma sexualidade saudável, é necessário que os jovens possam ter relações sexuais seguras, agradáveis e bem informadas, primando por uma autoestima positiva e respeito mútuo, sem riscos de DST, gravidez indesejada, violências, discriminação e coerção (PONTES, 2011). Com isso, o TO restabelece o diálogo entre as pessoas, promovendo relações livres e igualitárias, seja individual ou coletiva, envolvendo, dessa forma, diversos contextos do indivíduo, sejam habitacionais, econômicos, culturais, familiares, laços afetivos ou sociais diante de uma visão biopsicossocial, tornando-se instrumento para a construção de possibilidades de cuidado e de vida através da análise e discussão dos serviços de saúde (CAMPOS; PINTO;
SAEKI, 2014; SILVA et al, 2011).

Ao propor que os alunos tragam para a realidade questões voltadas ao desenvolvimento de sua sexualidade, conforme já reafirmado anteriormente, atores e espectadores, opressor e oprimido, passam a visualizar como seus comportamentos e concepções influenciam na vida um dos outros, possibilitando, consequentemente, uma troca de papeis e a discussão de comportamentos e posturas mais saudáveis, bem como a troca de informações acerca de questionamentos e dúvidas sobre seu próprio desenvolvimento.

As técnicas e as ferramentas encontradas dentro do TO são eficazes para a transformação dos valores sobre sexualidade, visto que ao ser desenvolvido, as ações cênicas amplificam atitudes que antes eram veladas e silenciadas como tabus sociais. Assim, é de extrema importância que a escola promova uma discussão mais crítica sobre assuntos voltados a sexualidade com a aplicação da ferramenta aqui estudada, em que o contato e a experiência que cada um dos envolvidos vivencia na construção e no decorrer da dramatização faz surgir uma perspectiva libertadora, podendo até ser considerada audaciosamente como "salvadora" dos problemas sociais, através de suas contribuições no desenvolvimento humano e consequentemente nas relações em sociedade. Perspectiva essa, pensado por Boal (1996).

\section{Desconstrução da sexualidade}

Através da utilização do TO, há uma melhor compreensão da relação dos jovens na sociedade, o que muitas vezes não é bem assimilada por eles na adolescência, visto que esta metodologia tem a capacidade de identificar e ressignificar suas necessidades. Ao se depararem com os diversos conflitos e mudanças características desta fase que influenciam diretamente em sua constituição como sujeito, eles podem desmistificar diversas concepções erroneamente enraizadas acerca da sexualidade.

Diante de uma visão biopsicossocial, o TO auxilia na compreensão afetiva sexual que está atrelada às relações, emoções e sentimentos dos jovens no processo de desenvolvimento humano, relacionando-se aos processos que compõem a evolução da sexualidade durante toda a sua vida (MINAS GERAIS, 2006).

Por ser um agente facilitador da relação educação sexual e desenvolvimento sexual saudável, as ferramentas como o teatro, música, dança, folclore e literatura presentes na estrutura do TO desconstroem as opressões, medos, angústias, dúvidas que o adolescente tenha sobre o tema, colaborando na aceitação positiva e salutar de suas mudanças físicas e psicológicas próprias desse período de 
vida, conforme apresentado no item anterior.

Ao identificar e discutir práticas nocivas baseadas em estereótipos e preconceitos sobre a sexualidade, ele problematiza as questões mais pontuadas pelos jovens durante as encenações e viabiliza o reconhecimento das diversidades sexuais, com o propósito de romper os estigmas ensejando a discussão sobre as diferenças de gênero, tal como rompe com a imagem "naturalizada" do ser-mulher e do ser-homem (SANTOS et al, 2008; ALVES; MOTA, 2015), possibilitando um modelo educativo mais libertador $\mathrm{e}$ abrangente.

Sendo assim, o TO configura-se como uma alternativa lúdica e artística à educação sexual dos jovens em qualquer espaço pedagógico e as instituições passam a ter uma nova ferramenta em mãos que abordam o sujeito como ser expressivo no mundo, não mais utilizando apenas cartilhas e disciplinas formais que não são muito eficazes no trabalho com os adolescentes (EVELYN; BIAR, 2015; DAYRELL, 2001).

É através da liberdade de expressão oferecida pelo TO que o indivíduo pode liberta-se das opressões cotidianas, visto que esta metodologia combate tanto às opressões individuais quanto coletivas (BEZERRA, 2015; BERGER; FONSECA, 2012). Ao possibilitar aos jovens uma educação sexual voltada às práticas de tal método dentro da escola, eles assumem seu corpo e sua sexualidade positivamente, sem preconceitos e estereótipos, diante de uma visão positiva e de um pensamento crítico e racional (GONÇALVES; FALEIRO; MALAFAIA, 2013).

Para Campos, Pinto e Saeki (2014) e Silva, Silva e Nascimento (2014), durante as encenações do TO, quando os alunos falam sobre suas emoções, são construídos novos conceitos e através disso, há uma redução nos comportamentos que geram opressão, pois, se possibilita aos adolescentes a realização de espetáculos a partir de suas próprias vivências e o desenvolvimento da cena transforma a realidade em um ambiente mais aberto ao diálogo e propício a aquisição de conhecimentos.

Perante a perspectiva apontada na relação da construção de um novo contexto, através das informações obtidas e a análise dos dados da pesquisa, o conceito de desenvolvimento saudável da sexualidade quando atrelado a realização do TO, propõe aos jovens uma maneira de refletir sobre o seu desenvolvimento, partindo inicialmente das escolas para todos os outros contextos do qual fazem parte.

Para dar ainda mais embasamento às informações utilizadas acima, Viana (2016) diz que o TO não ensina ou dá prioridade durante a atuação, porém, propõe métodos libertários, que mantém as exigências estéticas que apreciam a beleza cênica, nos quais seus pressupostos são seus conflitos internos. Para tanto, não se estabelece uma receita e/ou passo a passo de como deve ser seguido, mas faz com que os jovens tenham consciência de uma ação e reflexão com a finalidade aguerrida e transformadora no fazer do pensar.

Diante do exposto, fica evidente que o TO é uma metodologia de grande relevância a ser trabalhada em sociedade desde a infância até a vida adulta, porém, é a partir das instituições de ensino que ela pode ser melhor desenvolvida, pois é nesse ambiente que o jovem tem (ou deveria ter) os primeiros contatos com a educação sexual enquanto disciplina garantida pela lei $n$ o 9.394/1996 (BRASIL, 1996) que muitas vezes não é abordada pelos docentes na sala de aula.

\section{Uma metodologia de ensino para as escolas}

Sendo o professor, o profissional a liderar uma turma em sala de aula, cabe a ele funcionar como facilitador do processo educativo, proporcionando espaço para ações criativas de aprendizagem dos seus alunos. Para se usar o TO, há necessidade que haja tanto apoio da escola como preparo do professor.

Observando a pedagogia existente na construção do TO, Paulo Freire (2005) faz uma leitura de Augusto Boal e afirma que a Pedagogia do Oprimido refere-se a um processo de educação que é constituído por uma práxis de ação/reflexão/ação sobre o mundo, já que a opressão está relacionada às relações de poder estabelecidas socialmente e a prática educativa a atos coletivos de apropriação do conhecimento sistematizado. Então, o TO na escola passa a ser construído como uma metodologia de ensino baseada na participação e transformação social, em que não basta apenas produzir ideias, mas transformá-las em atos sociais, havendo a luta e libertação dos grupos sociais oprimidos em consonância com a filosofia da educação de Paulo Freire (TEIXEIRA, 2007; FILHO; MARQUES, 2012; SILVA; BALDIN; BONFIM, 2012).

Macedo (2013) e Araújo, Paiva e Bezerra (2015) afirmam que, no início de qualquer aprendizagem, o aluno enfrenta conflitos e é a partir disto que o professor deve agir buscando auxiliá-lo na busca de resoluções, pois o docente estimula um aprendizado mais avançado, propõe outro conflito oportunizando ao discente uma construção de conhecimento concreto e participativo que gera um novo aprendizado. A essa realidade, também se aplica as questões da sexualidade.

Ao utilizar o teatro como ferramenta, na prática, o conflito é apresentado através de uma peça. Após essa representação, é realizada uma análise do que foi abordado para que os alunos possam opinar sobre a cena e a modificar reencenando de acordo com suas vivências gerando novas representações. Com isso, é essencial que os educandos 
consigam se envolver nas propostas para se sentirem protagonistas e aliados dos educadores durantes as atividades produzidas pelo TO, pautando as demandas sociais no interior das instituições escolares e a luta pelos direitos humanos nos processos coletivos de apropriação do conhecimento e transformação social, refletindo sobre ações concretas para superação das relações de opressão (FREIRE, 2009).

Assim, não caberá aos educadores no decorrer da peça dizer para os jovens o que devem fazer durante apresentação, devem deixá-los seguir seus instintos e sentimentos que aparecem no momento da encenação para que se libertem do sentimento oprimido, trazendo para si uma reflexão de temas polêmicos e vivências que só apenas o jovem poderá interpretar naquele instante, fazendo com que pense e reflita segundo seu ponto de vista.

Portanto, espera-se que o educador possua sensibilidade para desenvolver uma metodologia de acordo com um viés crítico e um saber transformador que mais se ajuste aos anseios e, principalmente, a realidade em que estão situados os alunos. E diante das perspectivas aqui descobertas, o TO abre portas para uma nova visão sobre a realidade educativa, de maneira que o educando passa a entender o seu papel nesse processo de libertar-se, através das facilidades e dificuldades encontradas dentro e fora da escola e que refletem diretamente em seu comportamento.

Como metodologia, ele não ensina ou dá prioridades durante a atuação, porém, propõe um meio libertário que mantem as exigências estéticas da beleza cênica, onde seus pressupostos são os conflitos internos dos alunos. Para tanto, não se estabelece uma receita e/ou passo a passo de como deve ser seguido, mas faz com que os jovens tenham consciência de uma ação e reflexão com a finalidade aguerrida e transformadora no fazer pensar a realidade (VIANA, 2016; SILVA, 2016).

Com isso, o saber que é construído através do conhecimento crítico provoca nos sujeitos o desejo de transformar o mundo, por se constituírem como seres históricos e construtores das relações sociais, porém só é possível que isso ocorra através do diálogo entre educadores e educandos (FREIRE, 2005; JAPIASSU, 2005).

Desse modo, todos os envolvidos durante a realização do TO podem utilizá-lo como um método de libertação e conhecimento das questões que geram a opressão, principalmente aquelas voltadas à temática da sexualidade, visto que, de acordo com o processo de desenvolvimento vivenciado por cada um, estes geram consequências que influenciarão seu comportamento no decorrer de suas vidas.

Não obstante, é importante ressaltar que as contribuições promovidas pela metodologia do TO, podem ser identificadas em diversos outros temas que vão além do contexto da sexualidade. Dessa forma, podem ser utilizadas no debate sobre questões políticas e sociais, visto que sua aplicação pode ser exaltada em todos os contextos humanos, bastando que haja pessoas dispostas a realizá-los

\section{CONCLUSÕES}

O levantamento das informações apontada no presente artigo mostrou-se de suma importância para a comprovação dos resultados esperados, visto que foram encontradas pouquíssimas obras abordando o conjunto das duas temáticas e nenhuma com o mesmo problema de pesquisa, ao discutir o uso do TO no ambiente escolar, fato que torna este trabalho pioneiro.

Comprovou-se a hipótese de que o TO auxilia na promoção de um desenvolvimento saudável da sexualidade e na prevenção de comportamentos nocivos à saúde dos adolescentes, o que afeta diretamente seu desenvolvimento sexual. Além do mais, o estudo contribui com a sociedade, pois se percebe que ao se utilizar o TO, facilita-se o contato do indivíduo com suas vivências promovendo um espaço que permita a escuta de problemáticas vivenciadas pelos adolescentes, prevenindo o preconceito, sofrimento mental e dificuldades de relacionamento interpessoal. Assim, o acesso às informações e a problematização de temas referentes ao desenvolvimento $\mathrm{da}$ sexualidade na adolescência no contexto escolar é capaz de proporcionar aos jovens uma melhor compreensão sobre diversas questões.

Durante o processo de análise das variáveis, esbarrou-se em algumas dificuldades, a saber: como fazer para que o assunto sobre sexualidade pudesse ser abordado nas escolas sem um olhar preconceituoso ou de indução para vida social dos jovens? Como auxiliar o corpo docente a trabalhar com seus alunos sem que houvesse uma censura total a respeito da sexualidade? Como auxiliar esses professores na aplicação dessa nova metodologia, já que não é um método padrão nas escolas? Para tal desafio, o educador tem que estar empenhado para auxiliar seus alunos durante o processo de ensino-aprendizagem, fazer com que eles tenham um olhar voltado para si e possam refletir sobre o que desejam para seu futuro.

Logo, não há um avanço significativo no que diz respeito às metodologias utilizadas pelas escolas para lidar com seu alunado no que se refere à educação sexual, visto que a maior parte das intervenções realizadas são voltadas apenas as questões reprodutoras e de prevenção às doenças. Diante da importância de se debater sobre o conceito de sexualidade, mas devido ser o tema bem complexo e amplo, 
não é qualquer metodologia que se adequa, contudo esse objetivo pode ser completamente alcançado com o uso do TO. Sendo assim, não há dúvida de que ele auxilia os jovens entre 15 e 17 anos na compreensão de um desenvolvimento saudável da sexualidade dentro da escola por proporcionar a todos os envolvidos um contato direto com todo e qualquer aspecto da sexualidade, promovendo elaboração a partir da reflexão.

Portanto, diante da importância do assunto, torna-se necessário que as instituições invistam na capacitação dos professores, ofereçam um espaço físico para a escuta e realização das atividades cênicas bem como promovam a sensibilização de todos os envolvidos no meio escolar atribuindo-se uma responsabilização social frente às diversas questões que abarcam a sexualidade. Nesse sentido, a pesquisa mostrou-se bastante promissora devido às diversas contribuições que a temática proposta é capaz de possibilitar para a sociedade como um todo e para cada um dos envolvidos, sejam eles, atores ou espectadores, todos se beneficiam.

\section{REFERÊNCIAS}

ALENCAR, E.; FRANCISCHINI, R. Psicologia e educação: contribuições de Vigotski e Wallon. In: FRANCISCHINI, R.; VIANA, M. N. Psicologia Escolar: que fazer é esse? Brasília: Conselho Federal de Psicologia, p. 215, 2016.

ALVES, P.; MOTA, C. P. Identidade de gênero e orientação sexual na adolescência: natureza, determinantes e perturbações. Eletrônica de educação e psicologia. Porto, no 2, p. 45-61, 2015.

ARAÚJO, A. C.; PAIVA, I. L.; BEZERRA, M. A. O Teatro do Oprimido no atendimento socioeducativo: experiência de trabalho em Psicologia. VII jornada internacional de políticas públicas. São Luís, 2015.

ASSOCIAÇÃO INTERNACIONAL DE TEATRO DO OPRIMIDO AITO. Declaração de Princípios. 2012. Acesso em 10 de agosto de 2018 em http://www.theatreoftheoppressed.org/ en/index.php?nodelD=141.

BERGER, W.; FONSECA, D. P. R. O Teatro do Poder e o Teatro do Oprimido: formas de resistência e intervenção social em Caieiras Velhas Aracruz, ES (2006-2011). 2012. Dissertação (Mestrado em Serviço Social) - Pontifícia Universidade Católica do Rio de Janeiro, Rio de Janeiro, 2012.

BEZERRA, A. P. Verdade na Cena, Verdade na Vida: Boal e Stanislavski. Revista brasileira de estudos da presença. Porto Alegre, vol. 5, no 2, p. 413-430, 2015.

BOAL, A. O arco íris do desejo: o método Boal de teatro e terapia. Rio de Janeiro: Civilização Brasileira, 1996.

BOCK, B. A. M.; FURTADO, O.; TEIXEIRA, A. L. T. Psicologias: Uma introdução ao estudo de Psicologia. 13ㅇe ed. São Paulo: Editora Saraiva, 2001.

BORGES, S. L.; JÚNIOR, N. S. Augusto Boal e a educação: proposta para uma emancipação social através do TeatroFórum. Cadernos PDE. Paraná, vol. 1, 2013.

BRASIL. Lei no 9.394, de 20 de dezembro de 1996. Estabelece as diretrizes e bases da educação nacional. Diário Oficial da União, Brasília, 1996.

BRILHANTE, A. V. M.; CATRIB, A. M. F. Sexualidade na adolescência. Feminina. Fortaleza, vol. 39, no 10, 2011.

CALDEIRA, E. C. V. Promoção da saúde e desenvolvimento dos adolescentes: a educação sexual em contexto escolar. 2015. Tese (Doutorado em Enfermagem) - Universidade de Lisboa, Lisboa, 2015.

CAMPOS, F. N.; PINTO, M. P. P.; SAEKI, T. Teatro do oprimido: um teatro das emergências sociais e do conhecimento coletivo. Psicologia e sociedade. São Paulo, p. 552-561, 2014.

DAYRELL, J. T. Múltiplos olhares sobre a educação e cultura. Belo Horizonte: UFMG, 2001.

EVELYN, W.; BIAR, L. Teatro do Oprimido e performances de gênero: uma proposta de intervenção. Pesquisas em discurso pedagógico. Rio de Janeiro, 2015.

FILHO, J. P. P.; MARQUES, E. M. D. Teatro do Oprimido e educação: perspectivas para as práticas escolares na atualidade. ANPAE. Minas Gerais, 2012.

FREIRE, P. Pedagogia do oprimido. 45 ed. Rio de Janeiro: Paz e Terra, 2005.

FREIRE, P. Ação cultural para a liberdade e outros escritos. 12a ed. São Paulo: Paz e Terra, 2009.

GERHARDT T. E.; SILVEIRA, D. T. Métodos de pesquisa. Porto Alegre: Editora da UFRGS, p. 120, 2009.

GIL, A. C. Métodos e técnicas de pesquisa social. 6ㅇe․ São Paulo: Atlas, 2008.

GONÇALVES, R. C.; FALEIRO, J. H.; MALAFAIA, G. Educação sexual no contexto familiar e escolar: impasses e desafios. Holos. Rio Grande do Norte, vol. 5, p. 251-263, 2013.

JAPIASSU, R. Metodologia do ensino de teatro. 3으 ed. Campinas: Papirus, 2005.

MACEDO, F. J. C. As contribuições de Freire e Boal para a formação dos jovens e adultos: pedagogia do oprimido e teatro do oprimido. 2013. Dissertação (Mestrado em Teatro) - Departamento de Artes Cênicas do Instituto de Artes, Universidade de Brasília, Brasília, 2013.

MINAS GERAIS. Secretaria de estado de saúde. Atenção à saúde do adolescente. 1o ed. Belo Horizonte: SAS/MG, p. 99-101, 2006.

OLIVEIRA, E. C. S.; ARAÚJO, M. F. Aproximação do Teatro do 
Oprimido com a Psicologia e o Psicodrama. Psicologia ciência e profissão. Brasília, p. 340-355, 2012.

PONTES, A. F. Sexualidade: vamos conversar sobre isso? Promoção do desenvolvimento psicossexual na adolescência: implementação e avaliação de um programa de intervenção em meio escolar. 2011. Tese (Doutorado em Ciências de Saúde Mental) - Instituto de Ciências Biomédicas Abel Salazar da Universidade do Porto, Porto, 2011.

SANTOS, C. et al. Diversidade sexual na escola e a homofobia: a capacitação de professores como estratégia de intervenção. Fazendo gênero 8: corpo, violência e poder. Florianópolis, 2008.

SANTOS, T. R. P. Promoção da sexualidade saudável: relação entre satisfação sexual, assertividade e auto-eficácia em jovens adultos universitários. 2011. Dissertação (Mestrado em Psicologia Clínica e da Saúde) - Faculdade de Ciências Humanas e Sociais, Universidade Fernando Pessoa, Porto, 2011.

SILVA, A. C. P.; SILVA, M. C. C. B.; NASCIMENTO, C. M. O adolescente ressignificando seu lugar na sociedade contemporânea: o teatro do oprimido como ferramenta psicoeducativa. Educação, artes e Inclusão. vol. 9, n‥ 1, 2014.

SILVA, E. S.; BALDIN, T.; BONFIM, D. F. Teatro do Oprimido na escola: relato de experiência extensionista com adolescentes. 31으 SEURS. Paraná, 2012.

SILVA, I. F. O Teatro do Oprimido na escola: a arte de libertar os sujeitos. In: SECRETARIA DA EDUCAÇÃO (Paraná). Os desafios da escola pública paranaense na perspectiva do professor PDE. Pato Branco: Cadernos PDE, 2016.

SILVA, J. A. Um estudo sobre as especialidades dos/as nas propostas pedagógicas de educação de jovens e adultos EJA: tudo junto e misturado! 2010. Dissertação (Mestrado em Educação) - Faculdade de Educação, Universidade Federal de Minas Gerais, Belo Horizonte, 2010.

SILVA, J. J. S. et al. Desvelando os caminhos do Teatro do Oprimido como Estratégia de Reabilitação Psicossocial. Cuidado é fundamental. Campina Grande, 2011.

SILVEIRA, E. A arte do encontro: a educação estética ambiental atuando com o teatro do oprimido. Educação em revista. Belo Horizonte, v.25, n-03, p. 369-394, 2009.

TEIXEIRA, T. M. B. Dimensões sócio educativas do teatro do oprimido: Paulo Freire e Augusto Boal. 2007. Tese (Doutorado em Educação e Sociedade) - Universidade Autônoma de Barcelona, Barcelona, 2007.

VIANA, D. Teatro do oprimido na educação de jovens e adultos. Curitiba: Appris, 2016.

YANO, K. M.; RIBEIRO, M. O. O desenvolvimento da sexualidade de crianças em situação de risco. Escola de enfermagem da USP. São Paulo, p. 15-22, 2011.
Submissão: 05/09/2018

Aprovado para publicação: 04/12/2018 